\title{
Learning from experiences to determine quality in ethics education
}

\author{
Ercan Avci $^{1}$ (D)
}

Published online: 25 August 2016

(C) Springer International Publishing AG 2016

\begin{abstract}
Ethics is a prominent subject in almost all academic fields. However, the teaching of ethics is a controversial matter in terms of its aim, scope, method, and so on. Besides these points, the issue of quality in ethics education is another essential consideration which needs to define the concept of quality and determine its indicators as well as its measurement. Therefore, establishing certain standards and principles in ethics education may benefit all ethics programs across the world and create a global standardization at some points. Nevertheless, prior to proposing any method, model, standard, or indicator, looking at the existing situation of the current ethics programs would give opportunity to detect good practices, shortages, and shortcomings. In this sense, the aim of this paper was to review the literature on ethics education to exhibit the features of the present ethics programs and benefit from their experiences to determine what quality in ethics education is. The findings demonstrated that both students and educators believe that ethics education generates positive impact on ethical awareness, knowledge, and reasoning. However, the reviewed studies did not indicate explicit and adequate clues to draw a conclusion about what quality in ethics education is and which teaching method is the most effective.
\end{abstract}

Keywords Ethics education · Ethics teaching programs $\cdot$ Quality Perception

\section{Introduction}

Ethics is a common subject of almost all academic disciplines. However, the phrase quality in ethics education contains two major continuous debates. The first debate goes back to the time of Socrates in which it was discussed whether or not ethics could be taught. In regard to this point, a general consensus has been reached that ethics can be taught, even though there

Ercan Avci

avciercan@yahoo.com

1 Center for Healthcare Ethics-Duquesne University, Pittsburgh, PA, USA 
have been distinct arguments concerning the goals, models, and methods of ethics teaching (Finch and McAfee 2013; Hartman 2006; Pope and Kelly R. "Can Ethics be Taught?" Strategic Finance 2015). The second discussion is about the quality of education. Until recently, traditional approaches assessed education by mostly quantitative measures and focused on its productivity. Nevertheless, especially through UNESCO's endeavors, a humanistic perspective, which proposes the integration of learning individual practical skills with developing social competence, has emerged (Tawil and Sobhi and Marie Cougoureux. Revisiting learning: The treasure within assessing the influence of the 1996). This holistic approach is embodied in the Delors Report's four pillars: learn to know, learn to do, learn to live together, and learn to be (Burnett 2008). Therefore, the aim and quality of education may be considered in accordance with the perspective of these pillars.

Many disciplines use the term quality to highlight certain features and perceptions of services, outputs, and outcomes. However, the widespread focus on quality does not avoid the complexity and ambiguity of this concept (Golder et al. 2012). Quality is defined in numerous ways by different authors and scholars. According to Reeves and Bednar, each definition encompasses some strengths as well as weaknesses in terms of "measurement and generalizability, managerial usefulness, and consumer relevance (p. 435)" (Reeves et al. 1994). Due to the presence of many different components and a comprehensive domain of quality, the authors do not consider an all-inclusive, successful universal definition possible. Based on this perspective, as underscored by Reeves and Bednar, it may be difficult to produce a definition of quality to address and satisfy all elements, objectives, and expectations of all disciplines. Nonetheless, each academic field may outline a specific definition of quality in accordance with its unique characteristics. For instance, the Agency for Healthcare Research and Quality (AHRQ), an institution of the U.S. Department of Health and Human Services, describes quality in healthcare as "[d]oing the right thing (getting the health care services you need), [a]t the right time (when you need them), [i]n the right way (using the appropriate test or procedure) [t]o achieve the best possible results (p. 3)" (Agency for Healthcare Research and Quality 2005). On the other hand, the World Health Organization (WHO) explains quality in a health system by denoting six dimensions: effective, efficient, accessible, acceptable/patient-centered, equitable, and safe healthcare (World Health Organization. Quality of care: a process for making strategic choices in health systems. World Health Organization 2006).

Even though certain definitions, dimensions, and models may be borrowed from other academic areas to draw a general framework for quality in ethics education, it would be prudent to explore the existing situation of ethics education to get a more concrete picture. Furthermore, without possessing adequate data and information regarding the current ethics education programs and without utilizing actual experiences, it might be difficult to thoroughly appraise and measure the quality of ethics education. For this reason, the purpose of this paper was to review the literature on ethics education to look at the existing ethics teaching programs in order to figure out whether it is possible to explore some indications of what quality in ethics education is.

\section{Method}

The study reviews the literature through concentrating on the ethics programs' teaching scope, teaching method, and classroom model in light of students' and educators' 
perception, the performance of the programs, and the effectiveness of the programs. The teaching scope refers to the content of the programs, teaching hours, and teaching period (where the course is placed). In other words, the phrase "teaching scope" indicates what, how long, and when ethics should be taught. The teaching method demonstrates the issue of how ethics should be taught, whether by traditional methods, such as one-way lectures, homework readings, and writing exams or through contemporary teaching styles, like case discussions, small-group debates, and oral presentation. The classroom model is about whether ethics education should be given as a separate ethics course or as a concept of integrated into some other courses. Additionally, the issue of whether applying a conventional face-to-face classroom system or having online distance learning and whether ethics courses should be required or elective are examined under the classroom model.

The methodology of this paper was developed through the utilization of the focus subjects of the reviewed studies, to evaluate the perception of students and educators as well as the performance and effectiveness of the programs, in light of teaching scope, teaching method, and classroom model. Additionally, the relevance of perceptions, performance, and efficiency to the determination of quality and the examination of different processes in the identification and assessment of quality strongly persuaded the author to use this methodology, and divide ethics teaching into three categories: teaching scope, teaching method, and classroom model (Golder et al. 2012).

The relevant data was obtained by utilizing Duquesne University Gumberg Library's Discovery System-Quick Search that consists of about 20 databases including CINAHL, ERIC, PsycINFO, and Scopus®. The research was limited to the last 5 years from 2010 to 2015 inclusive. Data collection was carried out through reaching peer-reviewed, full text articles with subject terms "ethics" or "ethics education" and titles containing the phrases of "ethics education," "ethics teaching," or "ethics learning." In accordance with the defined scope, 34 scholarly articles were found: 26 research articles, 4 review articles, and 4 theoretical articles. The research articles covered the studies from 11 distinct academic disciplines: Nursing (7), Medicine and Health Science (6), Psychology (3), Business (2), Education (2), Ethics (1), Science and Engineering (1), Social Work (1), Public Relations (1), Information Systems (1), and Accounting (1) and were from the following countries: the United States (12), Australia (2), Taiwan (1), Belgium (1), Egypt (1), South Korea (1), Ireland (1), New Zealand (1), and Switzerland (1). Furthermore, 3 research studies were international, and 2 others were about North America (the United Stated and Canada).

\section{Review findings}

The diversity of the studies in terms of their scope, methodology, academic discipline, and research area allows for taking a broad picture of ethics education. However, it also obstructs the ability to make detailed inferences. Therefore, instead of heeding every conclusion of each study, the most striking parts were consolidated to form worthwhile results. In this context, the highlighted points of each study were systematically listed, and common matters were taken into account under the following subsections. 


\section{Teaching scope}

Nineteen studies point out certain issues about constituting an ethics curriculum, the basic features of content, and teaching hours. The most emphasized matter is the need for creating a convenient and applicable ethics curriculum. Six studies underscore the importance and necessity of generating a curriculum encompassing and demonstrating all the relevant subjects that are supposed to be taught (Boon 2011; Byrne et al. 2015; Fawzi 2011; Hudon et al. 2014; Lin et al. 2010; Park et al. 2012). For example, the study examining obstetrics-gynecology residency programs indicates "a lack of structured curricula" and suggests a well-designed, acceptable, and a universal curriculum "to achieve competency in the key dimensions of professionalism and interpersonal and communication skills (p. 397.e1, e7)" (Byrne et al. 2015). Similarly, Marwa M. Fawzi proposes forming an applicable "model curriculum" that helps medical students gain essential ethical knowledge and skills (p. 207) (Fawzi 2011). Furthermore, Anne Hudon et al., who reviewed the curricula of 27 Canadian occupational therapy and physiotherapy programs, stress the significance of developing an ethics curriculum to enhance the students' ethical decision making abilities (Hudon et al. 2014).

The content of the ethics programs is another point frequently emphasized. Contrary to the general assumption that the teaching of ethical theories is not supported, 6 studies, four of which are about nursing programs, underpin the learning of ethical theories (Boon 2011; Cannaerts et al. 2014; Fleischmann et al. 2011; Kalaitzidis and Schmitz 2012; Monteverde 2014; Vynckier et al. 2015). These studies show an explicit demand for teaching theories with ethical principles and codes. The international research study in public relations, carried out by Austina and Tothb, demonstrates that educators back "a fine balance between theory and application (p. 512) (Austina and Toth 2011). Additionally, Cannaerts, Gastmans, and de Casterle denote the integration of ethical theories and practices for effective outcomes (Cannaerts et al. 2014). Fleischmann, Robbins, and Wallace also emphasize the teaching of ethical theories, but they suggest teaching of theories for a better understanding of cultural differences (Fleischmann et al. 2011). Thus, besides improving ethics-related knowledge, skills, and abilities, strengthening cultural competency and sensitivity is another goal of ethics education. In this sense, ethics curricula should have a cross-cultural approach to satisfy cultural and social differences (Austina and Toth 2011).

The teaching of ethical principles and professional codes are also welcomed by both educators and students (Cannaerts et al. 2014; Kalaitzidis and Schmitz 2012; Laabs 2015; Lin et al. 2010; Loughran et al. 2014; Domenech Rodríguez et al. 2014). However, it is an intriguing finding that the studies in nursing and psychology accentuate the learning of ethical principles and codes more than other academic fields. This situation might be due to that in comparison with some other academic disciplines ethical principles and professional ethic codes have been much more grounded in medicine and health sciences. In regard to ethical principles, Beauchamp and Childress' four principles are more popular (Kalaitzidis and Schmitz 2012). However, according to some educators, teaching of these principles contains both advantages and disadvantages. On the one hand, learning the principles may allow students to have some tools to apply to ethical issues. On the other hand, it may preclude students from making comprehensive ethical judgements (Cannaerts et al. 2014).

The studies do not reveal a lucid picture concerning ethics programs' hours to draw a conclusion. Merely three articles touch on the hours of ethics teaching, and even these 
three studies show a wide range of hours between 4 and $32 \mathrm{~h}$ (Byrne et al. 2015; Kinsinger and Soave 2012; Park et al. 2012). Nevertheless, the studies exhibit an increase in as well as a demand for ethics education. For example, the international research study about ethics education in business schools indicates that ethics-related courses doubled in 5 year from 2005 to 2009 (Rasche et al. 2013). Some other studies also explore that educators especially request more ethics education (Austina and Toth 2011; Boon 2011; Byrne et al. 2015).

\section{Teaching method}

The teaching method of ethics is as important as teaching scope for the effectiveness of education. Teaching scope demands a well-designed curriculum, whereas the teaching method refers to the ways of actualizing the curriculum. A well-structured curriculum may not produce successful consequences without applying appropriate methods. In this context, the studies illustrate largely the implementation or recommendation of lectures (7 studies), case-based teaching ( 7 studies), group discussions ( 5 studies), and assigned readings (3). In other words, though educators' and students' approaches toward teaching methods differ slightly among distinct studies, lecture type, case-based teaching, and group discussions are most applied or demanded methods (Bruns et al. 2015; Canary et al. 2014; Cannaerts et al. 2014; Fawzi 2011; Griffith et al. 2014; Kinsinger and Soave 2012; Laabs 2015; Lin et al. 2010; Park et al. 2012; Domenech Rodríguez et al. 2014; Swisher et al. 2012; Vynckier et al. 2015).

The study reflecting nursing students' perspectives in Belgium shows that the students appreciate case-based learning with lectures, while quite more than half of the students believe group discussions have little or no impact on "their ethical development (p. 303)" (Vynckier et al. 2015) However, another study done in Belgium, which represents nursing students' and educators' viewpoints concerning teaching methods, indicates that besides case studies, the students value group discussions as well (Cannaerts et al. 2014). Similarly, the study in laboratory medicine training programs demonstrates that lecture-style teaching is popular across the world, whereas the study carried out by Carolyn A. Laabs in the United States disapproves of lectures (Bruns et al. 2015; Laabs 2015). However, Rodríguez et al. state that "lectures may be the most efficient and effective strategy for accomplishing ... the acculturation of ethical professionals (p. 246)" (Sanders and Hoffman 2010).

The phrases "case studies," (Vynckier et al. 2015) "case-based learning," (Johnson et al. 2012) "problem-based learning," (Lin et al. 2010) "case method," (Maruyama and Ueno 2010) "practical teaching method" (Fawzi 2011) are used by different studies, but all of them describe a teaching method utilizing tangible cases to clarify the understanding of learners in ethical confrontations. This method is regarded as rather useful by students, educators, and researchers (Canary et al. 2014; Cannaerts et al. 2014; Fawzi 2011; Johnson et al. 2012; Laabs 2015; Maruyama and Ueno 2010; Vynckier et al. 2015). According to Johnson and his colleagues, the effectiveness of case-based learning depends on the quality of used cases (Johnson et al. 2012). Furthermore, another interesting finding mentioned by two distinct studies is that even though case-based learning is considered effective and beneficial, in Taiwan and Japan lecture-style teaching is implemented because students from both countries are not used to or do not feel comfortable enough for an interactive learning 
system (Lin et al. 2010; Maruyama and Ueno 2010). This situation might be explained by cultural differences and their influence on teaching models in these countries.

Moreover, it is important to note that the aforementioned methods do not require substituting one of them for another. The application of distinct methods in the same curriculum is possible and plausible through the combination or integration of more than one method. For instance, the research done by Carolyn A. Laabs considers the implementation of case studies, group discussions, and readings essential (Laabs 2015). For this reason, lectures, case studies, discussion groups, presentations, film reviews, and readings or some combinations of them can be used in the same curriculum in accordance with their expected efficacy.

\section{Classroom model}

As mentioned above, there is an obvious request for increasing numbers of ethics-related courses and course hours. However, there is not a consensus on the classroom model of ethics education. Some educators and students are proponents of having separate ethics courses, whereas some others support the integration of ethics into the whole curriculum (Austina and Toth 2011; Boon 2011; Cannaerts et al. 2014; Fawzi 2011; Park et al. 2012; Rasche et al. 2013). In other words, though educators and students argue different views on whether ethics education should be given as a separate course or integrated course, they agree on providing more ethics education. On the other hand, Rasche, Gilbert, and Schedel claim that "an increase in the absolute number of ethics-related courses might be misleading, as effective change needs to address the underlying structure of [a] curriculum (e.g., in terms of addressed disciplines) and not only the number of courses (p. 82)" (Rasche et al. 2013). Therefore, ethics education does not only need quantitative increases, but also requires qualitative improvements.

The issue of whether having face-to-face ethics courses or online courses is another subject of the classroom model. Instead of asserting an alternative to a classical classroom system, some studies recommend online sources as supplementary to reinforce existing ethics education. David E. Bruns et al. point out "a desire for online resources to aid in ethics training in laboratory medicine (p. 118) (Bruns et al. 2015) Marwa M. Fawzi recommends "an online medical ethics forum" in order to both update developments in medical ethics and create a virtual area where physicians can talk about new ethical challenges (p. 207) (Fawzi 2011). Additionally, Godbold and Lees implement a web-based application called the Values Exchange employed to help users in ethical decision making procedures, and both clinicians and students evaluated this web-based technology as beneficial to alleviate the gap between ethical theories and practices (Godbold and Lees 2013). Similarly, Larysa Nadolny and her colleagues designed a project named the SciEthics Interactive providing virtual stimulations and gauged its results. According to their study, the virtual stimulations enhanced students' knowledge in ethical issues (Nadolny et al. 2013).

\section{Perception}

The perception of educators and students is crucial in ethics education. If an educator trusts a content and teaching method of a curriculum, she/he would be more productive. 
On the other hand, without students' perception of the usefulness of the teaching style and content, it would be difficult to contribute to students as much as expected. Students' active participation in courses is essential in terms of effectiveness of teaching ethics (Maruyama and Ueno 2010; Vynckier et al. 2015). CubieL . L. Lau states that "if students are willing to learn and perceive ethics education as useful, learning outcomes are improved (p. 581)" (Lau 2010). Furthermore, Heather E. Canary et al. stress the necessity of students' confidence in ethical debates (Canary et al. 2014). Thus, to establish a better framework of ethics educations, educators' and students' expectations, feelings, and perceptions should also be taken into account.

The studies explicitly indicate two points. The first one is that educators and students believe that ethics teaching positively influence students' ethical awareness, knowledge, and reasoning, but more ethics education should be provided to enhance students' ethical understanding (Byrne et al. 2015; Canary et al. 2014; Cannaerts et al. 2014; Kalaitzidis and Schmitz 2012; Lau 2010; Lin et al. 2010; Domenech Rodríguez et al. 2014). The study conducted by Cannaerts, Gastmans, and de Casterle explores that both students and educators accept that ethics education create substantial consequences, but the current devoted time to ethics courses is not adequate to study all ethical matters deeply, so the existing situation lead to perfunctory teaching (Cannaerts et al. 2014). Similarly, according to John Byrne and his colleagues, the directors of obstetrics and gynecology residency programs highly credit ethics education, but the existing curriculum with the designated time precluded achieving the desired results (Byrne et al. 2015). The second point is that despite not rejecting lectures and teaching of ethical theories, students tend to learn tangible ethical norms, codes, and principles to be able to apply them to their professional practices (Austina and Toth 2011; Boon 2011; Cannaerts et al. 2014; Fleischmann et al. 2011; Kalaitzidis and Schmitz 2012; Monteverde 2014; Vynckier et al. 2015). For these reason, problem or case-based learning, principles and codes, and group discussions are valued by students. However, some students and educators also place confidence in lectures and the teaching of theories (Monteverde 2014; Domenech Rodríguez et al. 2014; Vynckier et al. 2015). In this sense, certain studies suggest a combination of theories and practical information and applications (Austina and Toth 2011; Cannaerts et al. 2014).

\section{Performance}

The performance of the current programs illustrates how well the programs work. Therefore, without implementing a program, it is not possible to evaluate its performance. As the studies reveal that even some medical and nursing programs still do not offer formal and separate ethics courses, or the existing ethics teaching is unstructured in these programs (Bruns et al. 2015; Byrne et al. 2015; Lin et al. 2010; Park et al. 2012). Of course ethics is not only issue in medicine and health sciences; in light of contemporary moral values ethics is operative in all academic disciplines. Nonetheless, in comparison with several other fields, the confrontation of health professionals with ethical challenges is highly more likely due to the number of people and matters they encounter. However, an international survey in laboratory medicine training programs demonstrates that the majority of the programs do not have formal ethics teaching (Bruns et al. 2015). Likewise, the study done by Chiou-Fen Lin et al. in Taiwan proves 
that many nursing schools cannot provide a separate ethics course because of the lack of ethics instructors (Lin et al. 2010).

Even though all the present studies do not specify the details of programs regarding how well they function, these findings indicate that certain ethics programs perform well. Nonetheless, there are also many impediments diminishing the performance of ethics teaching. Limited time is one of these obstacles. The survey of 136 ethics educators from American Psychological Association accredited programs in the United States and Canada underlines the inadequacy of length of ethics courses which avoids studying of all substantial ethical topics (Domenech Rodríguez et al. 2014). Similar problems are expressed for the nursing programs in Taiwan as well as in Belgium (Cannaerts et al. 2014; Lin et al. 2010). Additionally, the shortage of educators and the lack of educators' experience in ethics education are also barriers affecting the performance of ethics teaching. An interesting point is that instructor-based difficulties are not merely the challenges of countries where ethics education has been recently flourishing, but also these problems can be seen in the United States where ethics has been a major academic field since the beginning of the 1960s (Lin et al. 2010; Maruyama and Ueno 2010). The study examining ethics education for the doctor of nursing practice exhibits "that many nurse faculty do not have formal education in ethics, leading to unintentional misinformation when such faculty are responsible for ethics education (p. 351)" (Laabs 2015). Furthermore, limited resources, unstructured curricula, and crowded curricula are some other handicaps of ethics education highlighted by the studies (Byrne et al. 2015; Lin et al. 2010; Rasche et al. 2013).

\section{Effectiveness}

Effectiveness refers to the results of an implemented ethics program. The distinction between performance and effectiveness might be confusing. However, in this paper, the term performance points out the application of a program regardless of its consequences, whereas effectiveness looks into the outcomes of a program. In other words, performance focuses on whether a program is applied successfully, while effectiveness concentrates on whether the results of an implemented program are effective.

In this context, the majority of the studies (18 studies) underscore the effectiveness or ineffectiveness of certain parts of the ethics programs. Fifteen studies find that particular methods of ethics teaching create positive consequences. In other words, an overwhelming number of studies accentuate that ethics education significantly increase students' ethical awareness, reasoning, sensitivity, judgement, knowledge, perspective, and personal values (Boon 2011; Canary et al. 2014; Cannaerts et al. 2014; Lau 2010; Lin et al. 2010; Nadolny et al. 2013; Park et al. 2012; Sanders and Hoffman 2010; Swisher et al. 2012). However, there is not an exact consensus on which teaching style is more effective. For instance, the survey of APA accredited programs considers lectures the more effective method, whereas in obstetrics and gynecology residency programs regards lectures as least effective way (Byrne et al. 2015; Domenech Rodríguez et al. 2014). Nonetheless, it can be stated that in regard to effectiveness, case-based learning is mostly preferred to lectures (Johnson et al. 2012; Lin et al. 2010; Domenech Rodríguez et al. 2014).

Contrary to the majority of positive perceptions, the research study reflecting thirdyear baccalaureate nursing students' perception about ethics education in Belgium 
shows that "the overall effectiveness of ethics courses is limited (p. 302)" (Vynckier et al. 2015). Nevertheless, the experimental design including two samples of business undergraduate students and carried out by Cubie L . L. Lau proves opposite findings that ethics education significantly impact the students' overall ethical awareness, orientation, reasoning, and sensitivity. However, the same study indicates that ethics education does not change the students' "view of the world (p. 581)" (Lau 2010). Moreover, the study conducted by Mary Jo Loughran et al. determines that the applied ethical activities did not increase the students' self-confidence (Loughran et al. 2014). Additionally, the comparative literature review done by Liu, Yao, and Hu demonstrates that ethics education in accounting is not as effective as it is in medicine and law (Liu et al. 2012). As a result, even though majority of the studies accept the effectiveness of ethics education, few studies assert either the overall or partial ineffectiveness of ethics teaching.

\section{Discussions}

Cathy L Rozmus and her colleagues state that "teaching ethics is not a hopeless task" and suggest grabbing students' attention by making ethical issues interesting (p. 825) (Rozmus et al. 2015). They also recommend supporting students to express themselves and to become open-minded about differences. Therefore, for better consequences of ethics education, certain suggestions can be implemented. Nonetheless, the first step in ethics teaching should be to clarify the aim of ethics education: whether the aim is to increase ethical awareness, judgement, and reasoning, to enhance professionals' knowledge to be able to respond to daily ethical confrontations, to foster cultural competence and sensitivity, to change or shape personal attitudes, behaviors, and view of the world, to provide students certain knowledge allowing them to find a job, or something else. Giacalone and Promislo explain the aim of ethics education as expanding students' horizon that requires empowering students with a vision "to live a virtuous life and build a virtuous world (p. 96)" (Giacalone and Promislo 2013). Therefore, Giacalone and Promislo ascribe a virtue-based task to ethics education. However, Kevin Breaux et al. determine that ethics learning does not have a significant function in obtaining positions in accounting, and they ask "if recruiters do not value ethics coursework ... should colleges and universities offer these courses? (p. 4)" (Breaux et al. 2010). Thus, contrary to the former approach, the latter idea circumscribes ethics education to only its tangible consequences.

John Tillson underlines that ethics, religions, and certain non-religious systems try to “answer the Socratic question 'how should one live?' (p. 681)" (Tillson 2011). In this context, he emphasizes the necessity for teaching religious as well as non-religious perspectives. However, he thinks it is not feasible to teach non-religious ideas beside a religious educational structure and concludes with recommending ethics education for teaching different values, thoughts, and approaches (Tillson 2011). Furthermore, Boucharda and Morris examine the Quebec Education Program's ethics and religious culture course and attribute the achievement of moral education programs to their attention to "the empirical, existential and social world of learners (p. 184)" (Boucharda and Morris 2012). Therefore, all the aforementioned positions address distinct aims and aspects of ethics education: instilling in students certain virtues and creating a virtuous 
world, obtaining specific ethical knowledge, skills, and abilities to find a job, teaching both religious and non-religious perspectives, and paying attention to learners' social world. In this sense, without identifying the purpose of ethics education, directly describing particular methods and models might be irrational.

Besides determining the aims of ethic education, deciding what to teach and how to teach are crucial questions in ethics education. Jensen and Greenfield recommend not limiting ethics education to teaching specific ethical theories, codes, and principles, but improving "students' ability to develop habits of mind" in order to increase the understanding of what, how, and why they act in case of encountering ethical issues (p. 155) (Jensen Gail and Bruce 2012). Moreover, it could be meaningful to underscore that ethics education should not merely focus on the development of individuals' ethical knowledge, skills, and abilities. Producing a global perspective recognizing and accepting cultural and social diversity as well as encouraging students to realize their place and role in society should also be the matters and aspects in which ethics education is engaged (Austina and Toth 2011; Canary et al. 2014).

As the studies clearly exhibit, though facing several shortcomings and impediments, ethics education creates positive and promising outcomes. To improve the current situation, more ethics education with well-established curricula is needed. However, this does not only mean to increase the number of ethics courses and hours, but also it necessitates structural changes (Rasche et al. 2013). Striking a balance between theories and practical cases, providing lectures with students' active participation, supporting group discussions and students' self-expression, and backing content and teaching methods with technological opportunities and sources would contribute to restructuring ethics education (Austina and Toth 2011; Bruns et al. 2015; Cannaerts et al. 2014; Godbold and Lees 2013; Hudon et al. 2014). Moreover, it should be taken into consideration that educators play a prominent role in effectiveness of ethics education. For this reason, the education of educators must come first because the lack of ethics educators and educators' experience in ethics are major obstacles to provide ethics education in an effective manner (Byrne et al. 2015; Laabs 2015; Maruyama and Ueno 2010).

On the other hand, in terms of the issue of quality, the reviewed studies do not provide a lucid picture to outline a general framework. In light of the findings of the studies, it may be emphasized that the existing ethics teaching programs are far from making a concrete quality assessment and measurement, due to certain reasons. First, quality indicates the acceptability of performance (Golder et al. 2012). Without performing ethics education, it would not be possible to gauge the quality of it. In this sense, ethics education has not settled in all academic disciplines adequately. For instance, although healthcare is a leading field in ethics, and the moral principles of the application of medicine goes back to the Hippocratic Oath, some medical and nursing schools across the world have not still had formal, satisfactory ethics education. In case of the absence or inadequacy of ethics teaching, quality-based discussions would not be grounded sufficiently. Therefore, under current circumstances, the reviewed studies naturally concentrate on the implementation of ethics programs rather than their quality. Second, without determining the purpose of ethics teaching, it may not be feasible and plausible to talk over quality. Goals are decisive factors in quality measurement that need to be decided prior to the application of ethics programs. Nevertheless, the studies do not demonstrate limpid findings to denote specific common goals for ethics education. Third, ethics education is supposed to improve 
recipients' (students) ethical knowledge, skills, and behaviors. In the event of quality measurement, these three areas should be appraised to determine whether expected consequences are produced. For this reason, quality indicators and assessment standards should be set. However, the reviewed studies do not supply sufficient clues how to form the indicators and standards.

Yet, it is believed that a general framework for quality in ethics education could be established through determining the goals of education, indicators of quality, and standards of measurement. The experiments of other academic disciplines may be utilized to shape core goals, indicators, and standards. However, the unique characteristics of ethics education should also be taken into consideration during this evaluation. Ethics is grounded in moral values, religious beliefs, cultural practices, and political perspectives. The outputs of ethics teaching are not as tangible, objective, and measurable as the outputs of business, marketing, or healthcare. Therefore, creating universal goals and standards as well as gauging the impact of ethics education on recipients might be difficult. Nonetheless, a teaching scope, teaching method, and classroom model-based classification as well as a perception, performance, and effectivenessfocused assessment may reify this abstract area to generate quality-related indicators and standards.

\section{Conclusion}

The findings demonstrated that though the necessity and usefulness of ethics education were confirmed by all the parties, the perception of the students, educators, and authors on the quality of the current programs indicated that there was still a great deal of room for improvement. Additionally, although the students, educators, and authors largely believed that ethics education was effective in enhancing ethical awareness, knowledge, and reasoning, certain shortcomings in the determination of teaching scope, teaching methods, and classroom models affect the results of ethics teaching and learning. The lack of dedicated time for ethics courses, the lack of educators' skills and experience in ethics, and the lack of formal ethics education were negative factors that influenced the performance of the programs. The studies showed that case-based teaching was the most desirable model. However, for a comprehensive understanding of ethics, an appropriate integration of theories and cases were also supported. Moreover, ethical principles and code-oriented teaching was welcomed by students. Even though there was an obvious need for formal ethics education, there was no concurrence on the issue of whether ethics education should be given as a stand-alone course or integrated in relevant courses.

The reviewed studies did not provide sufficient indications to explain what quality in ethics education is and which standards and indicators it has. However, the studies gave an opportunity to see students' and educators' perceptions and expectations about ethics education as well as the performance, benefits, shortages, and shortcomings of the current ethics programs which may help to draw a general framework as a starting point for examining quality in ethics education.

In light of an overall assessment of the studies, the following three suggestions are proposed. First, a sufficient number of formal ethics courses should be provided by educators having adequate education and experience in ethics. Second, for improving 
the performance and effectiveness of programs, well-structured curricula, theory- and practice-integrated courses, and a continuing education are recommended. Third, the education should give students an ethical perspective that transcends teaching certain ethical principles and codes. Ethics education should also strengthen cultural sensitivity, individual tolerance, and dialogue towards persons, groups, and societies with socially, economically, and culturally different characteristics.

\section{Limitations}

This study contains certain limitations. This literature review consists of 34 scholarly articles: 26 research articles, 4 review articles, and 4 theoretical articles. The research articles cover the studies from 11 distinct academic disciplines (3 international studies and the studies from 10 different countries). Therefore, the sole common point of the studies is ethics education. This is an advantage to draw a complete picture of ethics teaching. Nevertheless, the diversity in academic disciplines, research methodologies, and research approaches avoids digging into each matter in detail. Furthermore, even though different studies' show similar findings and results are assessed and integrated, the distinction among the research circumstances and focuses of each study may weaken some conclusions of this study.

Despite these limitations, it is believed that this study contributes to learning from experiences in order to determine the existing situation of ethics education and generate a framework for an effective ethics education. However, a global perspective to ethics education is still in a nascent stage. Therefore, more studies are recommended to elucidate quality in ethics education.

\section{References}

Agency for Healthcare Research and Quality. 2005. Guide to health care quality: how to know it when you see it. Rockville: Agency for Healthcare Research and Quality.

Austina, Lucinda L., and Elizabeth L. Toth. 2011. Exploring ethics education in global public relations curricula: Analysis of international curricula descriptions and interviews with public relations educators. Public Relations Review 37: 506-512.

Boon, Helen. 2011. Raising the bar: Ethics education for quality teachers. Australian Journal of Teacher Education 36(7): 76-93.

Boucharda, Nancy, and Ronald W. Morris. 2012. Ethics education seen through the Lens of Habermas's Conception of practical reason: The Québec Education Program. Journal of Moral Education 41(2): 171187.

Breaux, Kevin, Michael Chiasson, Shawn Mauldin, and Teresa Whitney. 2010. Ethics education in accounting curricula: Does it influence recruiters' hiring decisions of entry-level accountants? Journal of Education for Business 85: 1-6.

Bruns, David E., Carl A. Burtis, Ann M. Gronowski, Matthew J. McQueen, Anthony Newman, and Jon J. Jonsson. 2015. Variability of ethics education in laboratory medicine training programs: Results of an international survey. Clinica Chimica Acta 442: 115-118.

Burnett, Nicholas. 2008. The Delors report: A guide towards education for all. European Journal of Education 43(2): 181-187.

Byrne, John, Heather Straub, Laura DiGiovanni, and Julie Chor. 2015. Evaluation of ethics education in obstetrics and gynecology residency programs. American Journal of Obstetrics \& Gynecology 397: e1397-e8. 
Canary, Heather E., Julie L. Taylor, Joseph R. Herkert, Karin Ellison, Jameson M. Wetmore, and Carlos A. Tarin. 2014. Engaging students in integrated ethics education: A communication in the disciplines study of pedagogy and Students' roles in society. Communication Education 63(2): 83-104.

Cannaerts, Nancy, Chris Gastmans, and Bernadette Dierckx de Casterle. 2014. Contribution of ethics education to the ethical competence of nursing students: Educators' and Students' perceptions. Nursing Ethics 21(8): 861-878.

Domenech Rodríguez, Melanie M., Jennifer A. Erickson Cornish, Janet T. Thomas, Linda Forrest, Austin Anderson, and James N. Bow. 2014. Ethics education in professional psychology: A survey of American psychological association accredited programs. Training and Education in Professional Psychology 8(4): 241-247.

Fawzi, Marwa M. 2011. Medical ethics educational improvement, is It needed or not?! survey for the assessment of the needed form, methods and topics of medical ethics teaching course amongst the final years medical students faculty of medicine Ain shams university (ASU), Cairo, Egypt 2010. Journal of Forensic and Legal Medicine 18: 204-207.

Finch, Aikyna, and Ouida McAfee. 2013. Determining the importance of ethics education in business programs. Review of Management Innovation \& Creativity 5(17): 43-49.

Fleischmann, Kenneth R., Russell W. Robbins, and William A. Wallace. 2011. Information ethics education for a multicultural world. Journal of Information Systems Education 22(3): 191-201.

Giacalone, Robert A., and Mark D. Promislo. 2013. Broken when entering: The stigmatization of goodness and business ethics education. Academy of Management Learning \& Education 12(1): 86-101.

Godbold, Rosemary, and Amanda Lees. 2013. Ethics education for health professionals: A values based approach. Nurse Education in Practice 13: 553-560.

Golder, Peter N., Debanjan Mitra, and Christine Moorman. 2012. What is quality? an integrative framework of processes and states. Journal of Marketing 76: 1-23.

Griffith, Shannon M., Melanie M. Domenech Rodríguez, and Austin J. Anderson. 2014. Graduate ethics education: A content analysis of syllabi. Training and Education in Professional Psychology 8(4): 248252.

Hartman, Edwin M. 2006. Can We teach character? an Aristotelian answer. Academy of Management Learning \& Education 5(1): 68-81.

Hudon, Anne, Maude Laliberte, Matthew Hunt, Vickie Sonier, Bryn Williams-Jones, Barbara Mazer, Valérie Badro, and Debbie Ehrmann Feldman. 2014. What place for ethics? an overview of ethics teaching in occupational therapy and physiotherapy programs in Canada. Disability and Rehabilitation 36(9): 775780.

Jensen Gail, M., and Greenfield Bruce. 2012. Ethics education: Developing habits of mind through the use of pedagogical content knowledge. Physical Therapy Reviews 17(3): 149-156.

Johnson, James F., Zhanna Bagdasarov, Shane Connelly, Lauren Harkrider, Lynn D. Devenport, and Michael D. Mumford. 2012. Case-based ethics education: The impact of cause complexity and outcome favorability on ethicality. Journal of Empirical Research on Human Research Ethics 7(3): 63-77.

Kalaitzidis, Evdokia, and Karl Schmitz. 2012. A study of an ethics education topic for undergraduate nursing students. Nurse Education Today 32: 111-115.

Kinsinger, Stuart, and David Soave. 2012. Ethics education in chiropractic colleges: A north American survey. Journal of Manipulative and Physiological Therapeutics 35(6): 486-490.

Laabs, Carolyn A. 2015. Toward a consensus in ethics education for the doctor of nursing practice. Nursing Education Perspectives 36(4): 249-251.

Lau, Cubie L.L. 2010. A step forward: Ethics education matters. Journal of Business Ethics 92(4): 565-584.

Lin, Chiou-Fen, Meei-Shiow Lu, Chun-Chih Chung, and Che-Ming Yang. 2010. A comparison of problembased learning and conventional teaching in nursing ethics education. Nursing Ethics 17(3): 373-382.

Liu, Chunhui, Lee J. Yao, and Nan Hu. 2012. Improving ethics education in accounting: Lessons from medicine and Law. Issues in Accounting Education 27(3): 671-690.

Loughran, Mary Jo, Deanna Hamilton, and Cynthia Magistro. 2014. Psychology ethics education in a peerfacilitated laboratory setting. Training and Education in Professional Psychology 8(4): 285-291.

Maruyama, Yasushi, and Tetsu Ueno. 2010. Ethics education for professionals in Japan: A critical review. Educational Philosophy and Theory 42(4): 438-447.

Monteverde, Settimio. 2014. Undergraduate healthcare ethics education, moral resilience, and the role of ethical theories. Nursing Ethics 21(4): 385-401.

Nadolny, Larysa, Joan Woolfrey, Matthew Pierlott, and Seth Kahn. 2013. SciEthics interactive: Science and ethics learning in a virtual environment. Education Tech Research Dev 61: 979-999. 
Park, Mihyun, Diane Kjervik, Jamie Crandell, and Marilyn H. Oermann. 2012. The relationship of ethics education to moral sensitivity and moral reasoning skills of nursing students. Nursing Ethics 19(4): 568580 .

Pope, Kelly R. “Can Ethics be Taught?” Strategic Finance (2015): 42-47.

Rasche, Andreas, Dirk Ulrich Gilbert, and Ingo Schedel. 2013. Cross-disciplinary ethics education in MBA programs: Rhetoric or reality?". Academy of Management Learning \& Education 12(1): 71-85.

Reeves, Carol A. and David A. Bednar. Defining Quality: Alternatives and implications. Academy of Management Review 19, no 3 (1994): 419-445.

Rozmus, Cathy L., Nathan Carlin, Angela Polczynski, Jeffrey Spike, and Richard Buday. 2015. The brewsters: A new resource for interprofessional ethics education. Nursing Ethics 22(7): 815-826.

Sanders, Scott, and Kay Hoffman. 2010. Ethics education in social work: Comparing outcomes of graduate social work students. Journal of Social Work Education 46(1): 7-22.

Swisher, Laura Lee, Gisela van Kessel, Jones Mark, Beckstead Jason, and Edwards Ian. 2012. Evaluating moral reasoning outcomes in physical therapy ethics education: Stage, schema, phase, and type. Physical Therapy Reviews 17(3): 167-175.

Tawil, Sobhi and Marie Cougoureux. Revisiting learning: The treasure within assessing the influence of the 1996 Delors Report. Paris: UNESCO, 2013.

Tillson, John. 2011. In favour of ethics education, against religious education. Journal of Philosophy of Education 45(4): 675-688.

Vynckier, Tine, Chris Gastmans, Nancy Cannaerts, and Bernadette Dierckx de Casterle. 2015. Effectiveness of ethics education as perceived by nursing students: Development and testing of a novel assessment instrument. Nursing Ethics 22(3): 287-306.

World Health Organization. Quality of care: a process for making strategic choices in health systems. World Health Organization, 2006. 